\title{
Instantaneous Symmetrical Component based Virtual Oscillator Control
}

This paper was downloaded from TechRxiv (https://www.techrxiv.org).

\section{LICENSE}

CC BY 4.0

SUBMISSION DATE / POSTED DATE

$10-02-2022$ / 11-02-2022

\section{CITATION}

Ghosh, Ritwik; Tummuru, Narsa Reddy; Rajpurohit, Bharat Singh (2022): Instantaneous Symmetrical Component based Virtual Oscillator Control. TechRxiv. Preprint.

https://doi.org/10.36227/techrxiv.19152716.v1

$\mathrm{DOI}$

10.36227/techrxiv.19152716.v1 


\title{
Instantaneous Symmetrical Component based Virtual Oscillator Control
}

\author{
Ritwik Ghosh, Narsa Reddy Tummuru, Senior Member, IEEE, and Bharat Singh Rajpuohit, Senior Member, IEEE
}

\begin{abstract}
Virtual Oscillator (VO) control is a timedomain control strategy for grid-supporting and gridforming inverters. Existing VO Controllers (VOC) use single two-dimensional non-linear limit cycle oscillators to produce the $\alpha$ and $\beta$ components of control voltages. The $\alpha$ and $\beta$ components of output currents of the inverter are used as feedback to the controller. Zero component entities are neglected both in the feedback and output of the controller. Control over the $\alpha$ and $\beta$ axis is not decoupled. This paper has introduced instantaneous symmetrical component based VOC to improve the properties of VOCs, stated earlier. The proposed VOC uses three AndronovHopf oscillators to generate the positive, negative, and zero sequence components of the control voltages. The outputs of the oscillators are modified as required by each sequence. The performance of the proposed VOC is verified in two conditions, which are not reported in the earlier literature of VOCs. The first condition is grid-supporting operation in presence of unbalanced grid voltages. The second condition is grid-forming operation when single-phase and threephase inverters are integrated into the same islanded system. The proposed VOC can be configured to provide either $(\omega-\mathrm{P}, \mathrm{V}-\mathrm{Q})$ or $(\mathrm{V}-\mathrm{P}, \omega-\mathrm{Q})$ droop. This paper has presented $(\omega-P, V-Q)$ droop.
\end{abstract}

Index Terms - Grid forming, Grid supporting, Hybrid microgrid, Instantaneous symmetrical component, Limit cycle oscillator, Unbalanced grid voltage, Virtual oscillator controller.

\section{INTRODUCTION}

$\mathrm{V}$ irtual Oscillator (VO) control strategy is a new and promising technique for grid-forming and grid-supporting power electronic converters. VO controllers (VOC) make inverters mimic the dynamics of non-linear limit-cycle oscillators [1]-[3]. In recent years, remarkable research works are done to improve the performance and functionality of VOCs. In steady-state, the functionalities of conventional droop control are subsumed by VOC [4]. At the same time, because of time-domain implementation, VOC provides better dynamic performance than conventional droop controllers [5]-[7]. Over the course of time, different VOC models such as dead-zone, Van-der-Pol, dispatchable VOC (dVOC), Andronov-Hopf [8][12] are introduced. Dead-zone and Van-der-Pol oscillator have a few limitations. They can incorporate only one input as feedback which is not well-suited for three-phase operations [13]. Seamless control over the active and reactive power is not possible without an additional control loop [12]. A Van-der-Pol oscillator can achieve lower harmonic content in the output voltage only at an expense of sluggish dynamic response [9]. Andronov-Hopf oscillator based VOCs overcome the mentioned limitations of dead-zone and Van-der-Pol oscillator based VOCs [12]. Dispatchable VOC (dVOC) is synthesized in a top-down design procedure [10]. The elemental form of dVOC is similar to an Andronov-Hopf VOC [12].

Some very important system-level modifications and implementation techniques for VOC are reported in the literature. A Van-der-Pol oscillator is used in grid-connected mode with the help of an additional control loop in [14], [15]. The additional control loop helps to achieve decoupled control over the active and reactive power output. A hierarchical control structure for Van-der-Pol oscillator based VOC is introduced in [16] to enable seamless transition between islanded operation and grid-connected operation. A unified control strategy for dVOC is presented in [17] to enable gridforming and grid-following operations using the same dVOC. A virtual impedance based current limiter for dVOC is also introduced in [17]. The transient stability of the controller, proposed in [17] during low voltage fault is analyzed in [18]. Virtual impedance based selective harmonic current rejection technique for VOC is presented in [19]. The non-linear current source of the Van-der-Pol oscillator is modified in [20] to reduce the third harmonic component of the output control voltage. An observer-based active damper is used in [21] to improve the damping efficiency of VOC. A reduced-order model of dispatchable VOC with nested current and voltage loop is presented in [22]. The nested current loop is equipped with a current reference limiter and an anti-windup control to provide over-current protection. VOC is used to control distributed power filters in dc system for selective ripple attenuation in [23].

However, two specific conditions are not reported by the earlier literature of VOCs. The conditions are as follows

- The grid-supporting operation in presence of unbalanced grid voltages

- The grid-forming operation when single-phase and threephase sources are integrated into the same islanded system.

The motivations, behind addressing the two mentioned conditions are as follows. Voltage unbalances of $2-15 \%$ for a short duration (3cycle $-1 \mathrm{~min}$ ) and $0.5-5 \%$ for steady-state duration are very common in electrical power systems [24]. It is revealed that voltage unbalance is countable for nearly $32.3 \%$ of all the Power Quality (PQ) events in various industries [25] and it comes with serious adverse effects on loads [25]. Voltage imbalance also has adverse effects on the reliability of the electrical network [26]. Distributed energy sources are expected to provide voltage support to the grid in presence of unbalanced grid voltages [27]-[29]. In grid-forming mode, the integration of single-phase and three-phase sources into the same threephase four-wire system improves the utilization of the distributed renewable energy sources [30].

This paper has introduced instantaneous symmetrical component based VOC to improve three properties of existing VOCs which are as follows

- The parameters of VOC are designed to produce only 
balanced three-phase control voltages [12]. In the operating region the amplitudes of the two orthogonal control voltages $\left(v_{\alpha}\right.$ and $v_{\beta}$ ) are always equal (i.e $\left.\left|V_{\alpha}\right| \approx\left|V_{\beta}\right|\right)$. The phase portrait of an Andronovo-Hopf oscillator is shown in Fig. 1. The shape of the phase portrait is very close to a circle.

- Single Two-Dimensional (2D) oscillator is used to control three-phase inverters in earlier literature [12], [13]. The three control voltages (i.e. $v_{a}, v_{b}, v_{c}$ ) are derived from the two output voltages (i.e. $v_{\alpha}, v_{\beta}$ ) of the $2 \mathrm{D}$ oscillator. The controller includes only two components of the three-phase inverter currents (i.e. $i_{\alpha}, i_{\beta}$ ) as feedback. Zero component entities are neglected both in the feedback and output of the controller.

- The Positive, negative, and zero sequence droops cannot be embedded on a single limit cycle oscillator because a non-linear oscillator does not follow the superposition principle.

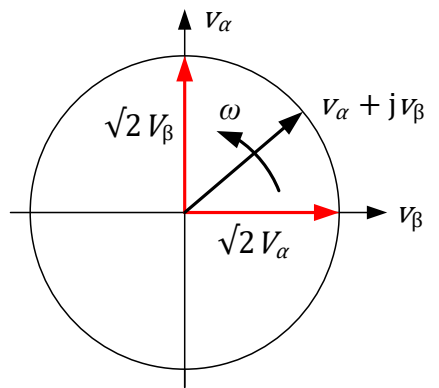

Fig. 1. Phase portrait: Andronov-Hopf limit cycle oscillator

The proposed instantaneous symmetrical component based VOC generates the control voltages of positive, negative, and zero sequences by using three Andronov-Hopf oscillators. The three Andronov-Hopf oscillators are the main building blocks of the proposed VOC. The basic model of the Andronov-Hopf oscillator [12] is modified as required by each sequence. The outputs of three oscillators are added up to generate the threephase control voltages. The three-phase output currents of the inverter are converted to symmetrical components and incorporated into the three oscillators. All the components of the control voltages, as well as the three-phase inverter currents, are considered by the proposed VOC. The detailed mathematical model of the proposed instantaneous symmetrical component based VOC is presented in Section III. The proposed VOC can be configured to provide either $(\omega-\mathrm{P}, \mathrm{V}-\mathrm{Q})$ or $(\mathrm{V}-\mathrm{P}, \omega-\mathrm{Q})$ droop. This paper has presented $(\omega-\mathrm{P}, \mathrm{V}-\mathrm{Q})$ droop only in analysis and experiments. Simulation studies and hardware experiments are presented in Section IV and Section $\mathrm{V}$ respectively to validate the proposed VOC.

\section{DROOP RESPONSE OF AN EXISTING VOC IN PRESENCE OF UNBALANCED GRID VOLTAGES}

Andronov-Hopf oscillator based VOC is first introduced in [12] where the controller mimics the dynamics of a so-called Andronov-Hopf system [31]. The output voltage dynamics of the Andronov Hopf VOC is presented in [12] as

$$
\begin{aligned}
{\left[\begin{array}{c}
\dot{v}_{\alpha} \\
\dot{v}_{\beta}
\end{array}\right]=} & {\left[\begin{array}{cc}
\frac{\xi}{k_{v}^{2}}\left(2 V_{n}^{2}-\left\|v_{\alpha \beta}\right\|^{2}\right) & -\omega_{n} \\
\omega_{n} & \frac{\xi}{k_{v}^{2}}\left(2 V_{n}^{2}-\left\|v_{\alpha \beta}\right\|^{2}\right)
\end{array}\right]\left[\begin{array}{l}
v_{\alpha} \\
v_{\beta}
\end{array}\right] } \\
& -\frac{k_{v} k_{i}}{C}\left[\begin{array}{cc}
\cos \varphi & -\sin \varphi \\
\sin \varphi & \cos \varphi
\end{array}\right]\left[\begin{array}{l}
i_{\alpha}-i_{\alpha}^{*} \\
i_{\beta}-i_{\beta}^{*}
\end{array}\right]
\end{aligned}
$$

$$
\left[\begin{array}{l}
i_{\alpha}^{*} \\
i_{\beta}^{*}
\end{array}\right]=\frac{2}{3\left\|v_{\alpha \beta}\right\|^{2}}\left[\begin{array}{cc}
v_{\alpha} & v_{\beta} \\
v_{\beta} & -v_{\alpha}
\end{array}\right]\left[\begin{array}{l}
P^{*} \\
Q^{*}
\end{array}\right]
$$

where, $V_{n}, \omega_{n}, P^{*}$ and $Q^{*}$ are the nominal voltage and angular frequency, reference active and reactive powers respectively. Throughout this paper, superscripted "* " is used to indicate the reference parameters. The parameters, $k_{v}$ and $k_{i}$ are the voltage and the current scaling factors between the physical inverter and the virtual oscillator. The parameters, $\xi$, and $C$ are the speed constant and the virtual capacitor of the VOC. The parameter $\varphi$ is a user-defined rotational angle. With, $\varphi=0$ and $\varphi=\pi / 2$ the controller provides $(\mathrm{V}-\mathrm{P}, \omega-\mathrm{Q})$ and $(\omega-\mathrm{P}, \mathrm{V}-\mathrm{Q})$ droops respectively. Throughout this paper the rotational angle, $\varphi$ is taken equal to $\pi / 2$. The steady-state and the dynamic characteristics of VOC such as the steady-state frequency and voltage regulation, the rise time of the output voltage, the time constant of real power output are determined by the value of the parameters mentioned earlier. The design procedure of $k_{v}, k_{i}$, $\xi$, and, $C$ is presented in [12]. The active and the reactive power droop characteristics of the VOC are derived by time-averaging (1) and (2) as follows

$$
\begin{gathered}
\omega=\omega_{n}-\frac{k_{v} k_{i}}{3 C V^{2}}\left(P-P^{*}\right) \\
0=\frac{\xi}{k_{v}^{2}} V\left(2 V_{n}^{2}-2 V^{2}\right)-\frac{k_{v} k_{i}}{3 C V}\left(Q-Q^{*}\right)
\end{gathered}
$$

Next, in presence of balanced grid voltages, it can be written that

$$
\begin{gathered}
P_{a}=P_{b}=P_{c} ; P_{a}^{*}=P_{b}^{*}=P_{a}^{*} \\
P=P_{a}+P_{b}+P_{c} ; P^{*}=P_{a}^{*}+P_{b}^{*}+P_{a}^{*} \\
Q_{a}=Q_{b}=Q_{c} ; Q_{a}^{*}=Q_{b}^{*}=Q_{a}^{*} \\
Q=Q_{a}+Q_{b}+Q_{c} ; Q^{*}=Q_{a}^{*}+Q_{b}^{*}+Q_{a}^{*}
\end{gathered}
$$

Hence, the desired droops for the individual phases are

$$
\begin{gathered}
\omega_{z}=\omega_{n}-\frac{k_{v} k_{i}}{C V_{z}^{2}}\left(P_{z}-P_{z}^{*}\right) \\
0=\frac{\xi}{k_{v}^{2}} V_{z}\left(2 V_{z n}^{2}-2 V_{z}^{2}\right)-\frac{k_{v} k_{i}}{C V_{z}}\left(Q_{z}-Q_{z}^{*}\right)
\end{gathered}
$$

where, $z \in a, b, c$. The solid lines in Fig. 4 and Fig. 5 present (10) and (9) respectively. The droop characteristics of all three phases coincide. The actual droop responses of the VOC in presence of different unbalanced grid voltages are observed using a simulation study. The schematic diagram of the system, considered for the simulation study is shown in Fig. 2. The specifications of the controller and the system are provided in Table I .

Table I: Specifications of VO controller and power system for simulations

\begin{tabular}{lll}
\hline \hline Symbol & Description & Value \\
\hline$V_{n}$ & Nominal rms voltage & $80 \mathrm{~V}$ \\
$\omega_{n}$ & Nominal frequency & $2 \pi 60 \mathrm{rad} / \mathrm{s}$ \\
$\xi$ & Speed constant & $151 / \mathrm{sV}^{2}$ \\
$k_{v}$ & Voltage scaling factors & $80 \mathrm{~V} / \mathrm{V}$ \\
$k_{i}$ & Current scaling factors & $0.2 \mathrm{~A} / \mathrm{A}$ \\
$C$ & Virtual capacitance & $0.26 \mathrm{~F}$ \\
$P^{*}$ & Reference active power & $850 \mathrm{~W}$ \\
$Q^{*}$ & Reference reactive power & $0 \mathrm{VAR}$ \\
$V_{g}$ & Grid voltage (rms) & $80 \mathrm{~V}$ \\
\hline \hline
\end{tabular}


Three-Phase Source

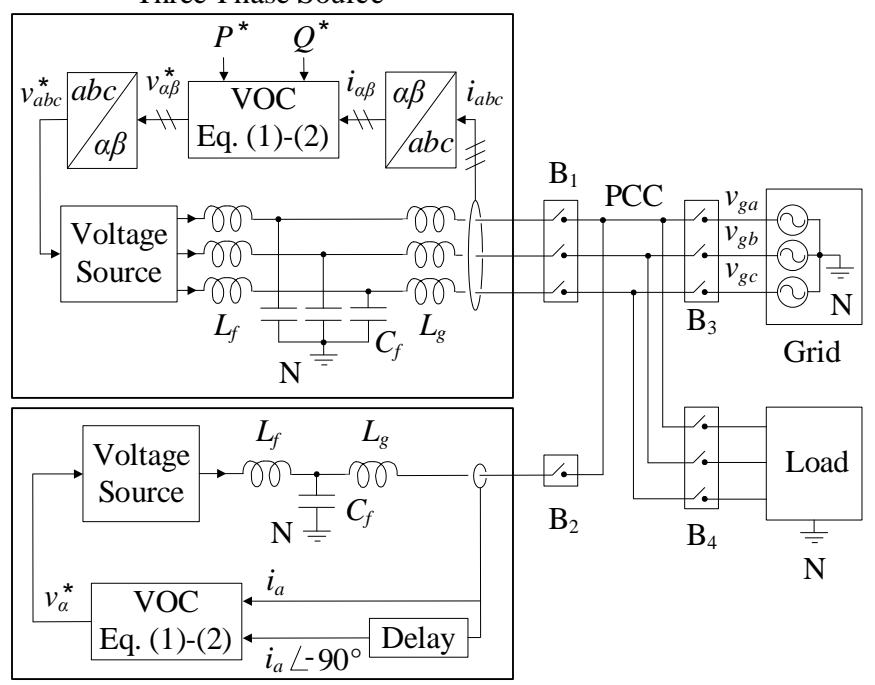

Single-Phase Source

Fig. 2. Existing VOC: Grid-supporting operation in presence of unbalanced grid voltages and grid-forming operation when a single-phase and a three-phase source are integrated into the same islanded system

The three-phase voltage source is connected to the grid using the breakers, $\mathrm{B}_{1}$ and $\mathrm{B}_{3}$. The load is connected to the PCC using the breaker, $\mathrm{B}_{4}$. The breaker, B2 is kept off.

The rms voltage amplitudes of phase-b and $c$ of the grid are kept constant at the nominal value. The rms voltage amplitude of phase-a of the grid is changed from $100 \%$ to $85 \%$ of the nominal value in 6 equal discrete steps $(2.5 \%$ per step). In presence of unbalanced grid voltages, the performance of the existing VOC deteriorates.

The waveforms of the output source currents when $\left(\left|V_{g a}\right|=\right.$ $\left|V_{g b}\right|=\left|V_{g c}\right|=1$ P.U.) and ( $\left|V_{g a}\right|=0.9$ P.U.; $\left|V_{g b}\right|=\left|V_{g c}\right|=1$ P.U.) are shown in Fig. 3 (a). The phasor diagrams of the output phase currents of the voltage source and the phase voltages of the grid are presented in Fig. 3. (b) and (c). In presence of balanced grid voltages, the output currents of individual phases are approximately $3.53 \mathrm{~A}$ (rms). The power factors of individual phases are very close to unity. The amplitude of the grid-voltage of phase-a is then reduced by $10 \%$. It is observed from Fig. 3 . (a) that the amplitude of the output current of phase-a is increased as expected to support the respective phase with reactive power. From Fig. 3. (c), it is observed that phase-a of the voltage source provides reactive power. However, Fig. 4 shows that the value of the reactive power output differs a lot from the preset droop. Also, Fig. 3. (c) shows that phase-b and phase-c consume reactive power. It is completely undesirable as the amplitude of the grid-voltages of phase-b and phase-c are kept constant at 1 P.U. The active power outputs of individual phases are also shifted far from the preset droop. The detailed quantitative analysis is presented in Subsection $\mathrm{A}$ and Subsection B.

\section{A. Shifting of the operating points: Reactive Power Output}

The solid black line in Fig. 4 represents the preset reactive power droop characteristic (10). The reference reactive power is set to $0 \mathrm{VAR}$. That is why in presence of nominal grid voltage i.e. $80 \mathrm{~V}$ individual phases inject 0 VAR to the grid.

The amplitude of the grid-voltage of phase-a is reduced to $85 \%$ of its nominal value in 6 equal discrete steps $(2.5 \%$ per step). The amplitudes of the grid-voltages of phase-b and phasec are kept constant at $1 \mathrm{P}$.U. The reactive power outputs of individual phases of the voltage source are plotted in Fig. 4. With the decrease in the voltage amplitude, the reactive power output of phase-a is increased as expected. However, the reactive power output of phase-a is increased at a much higher rate than the preset droop. The voltage source at Phase-b and phase-c starts consuming reactive power due to the decrease in the amplitude of the grid-voltage of phase-a. The arrows in Fig. 4 indicate the shifting of the operating point.

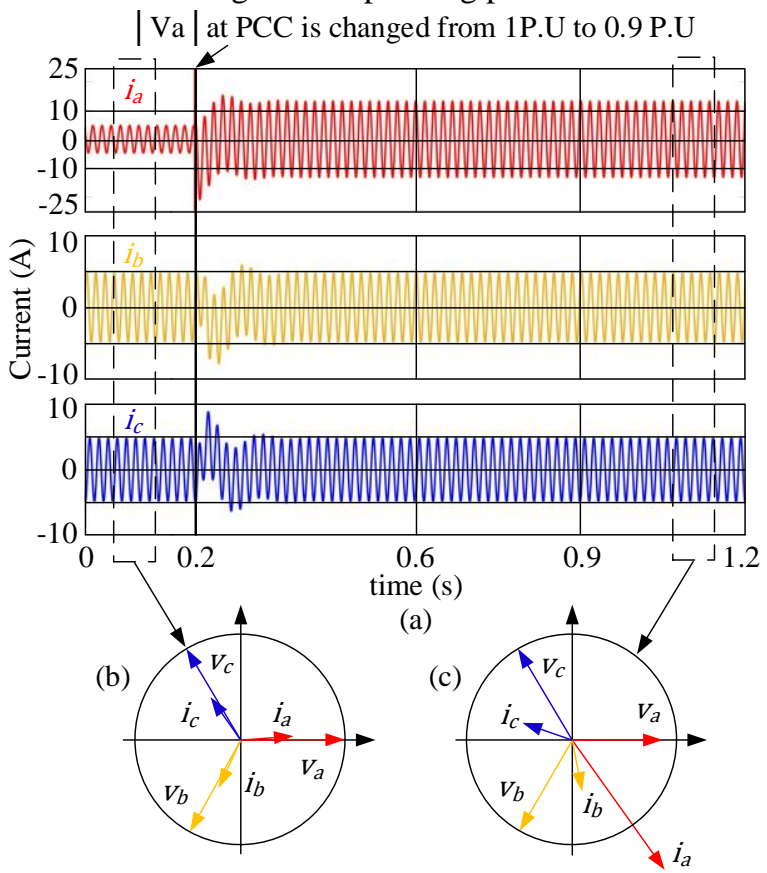

Fig. 3. Existing VOC in grid-supporting mode: (a) Output phase currents of the voltage source in presence of balanced and unbalanced grid voltages; The phasor diagrams of the output phase currents of the voltage source and the phase voltages of the grid in presence of (b) balanced grid voltages (c) unbalanced grid voltages

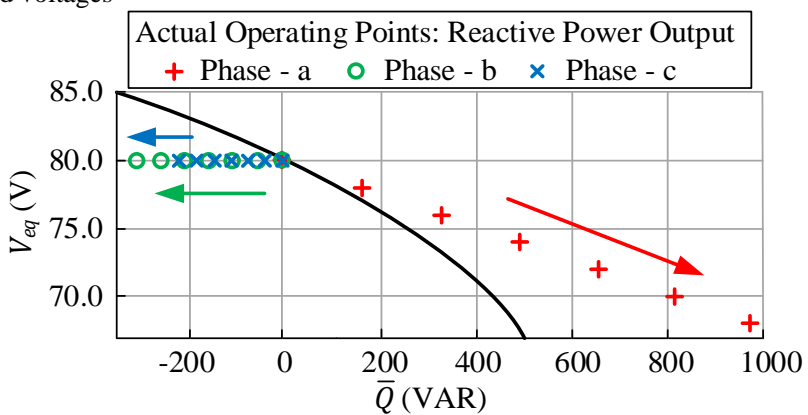

Fig. 4. Grid-supporting performance of existing VOC in presence of unbalanced grid voltages: desired reactive power droop characteristic and the actual operating points

\section{B. Shifting of the operating points: Active Power Output}

The red line and the blue line in Fig. 5 represent the preset active power droop characteristic (9) when the phase voltage is 1 P.U and 0.85 P.U respectively. The reference three-phase active power, $\mathrm{P}^{*}$ is set to $850 \mathrm{~W}$. In presence of balanced grid voltages, all the individual phases inject $283.33 \mathrm{~W}$ into the grid. The active power outputs of individual phases with every $2.5 \%$ decrease in the amplitude of the grid-voltage of phase-a are plotted in Fig. 5. The active power output of phase-a is increased and, phase-b and phase-c are decreased even if the 
grid frequency is kept constant at $60 \mathrm{~Hz}$.

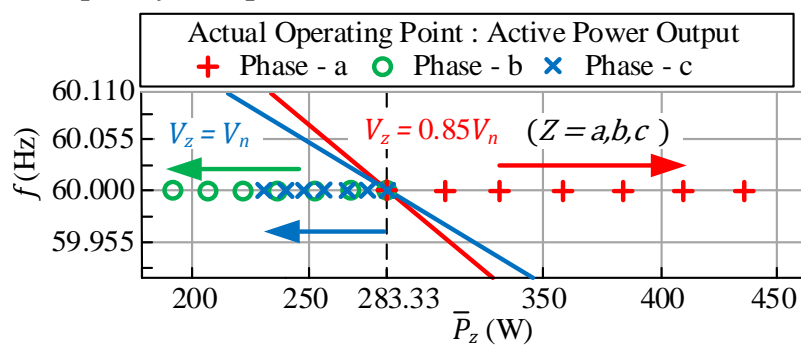

Fig. 5. Grid-supporting performance of existing VOC in presence of unbalanced grid voltages: desired active power droop characteristic and actual operating points

The results of the simulation study indicate that the gridsupporting performance of the existing VOC is not very desirable in presence of unbalanced grid voltages.

\section{The Proposed Instantaneous SyMmetricAL COMPONENT BASED VO CONTROLLER}

The schematic diagram of the proposed VOC is presented in Fig. 6. Three Andronov-Hopf oscillators are used to generate the positive, negative, and zero sequence control voltages. The rotational angle, $\varphi$ of the Andronov-Hopf oscillators is taken equal to $\pi / 2$.

\section{A. Oscillator for the positive sequence control voltages}

The model of the oscillator for generating the positive sequence control voltages is given by

$$
\begin{aligned}
& \dot{v}_{+\alpha}=\frac{\xi}{k_{v}^{2}}\left(2 V_{n}^{2}-\left\|v_{+\alpha \beta}\right\|^{2}\right) v_{+\alpha}+\omega_{n} v_{+\beta}+\frac{k_{v} k_{i}}{C}\left(i_{+\beta f}\right) \\
& \dot{v}_{+\beta}=\frac{\xi}{k_{v}^{2}}\left(2 V_{n}^{2}-\left\|v_{+\alpha \beta}\right\|^{2}\right) v_{+\beta}-\omega_{n} v_{+\alpha}-\frac{k_{v} k_{i}}{C}\left(i_{+\alpha f}\right)
\end{aligned}
$$

where, $\omega_{n}, V_{n}, i_{+\alpha f}, i_{+\beta f}$ are the nominal frequency, nominal voltage, $\alpha$ and $\beta$ components of the feedback respectively.

\section{B. Oscillator for the negative sequence control voltages}

The nominal frequency and the voltage amplitude of the oscillator which produces the negative sequence control voltages are $\omega_{n}$ and 0 respectively. The model of the oscillator is given by

$$
\begin{gathered}
\dot{v}_{-\alpha 1}=\frac{\xi}{k_{v}^{2}}\left(2 V_{n}^{2}-\left\|v_{-\alpha \beta 1}\right\|^{2}\right) v_{-\alpha 1}+\omega_{n} v_{-\beta 1}+\frac{k_{v} k_{i}}{C}\left(-i_{-\beta f}\right) \\
\dot{v}_{-\beta 1}=\frac{\xi}{k_{v}^{2}}\left(2 V_{n}^{2}-\left\|v_{-\alpha \beta 1}\right\|^{2}\right) v_{-\beta 1}-\omega_{n} v_{-\alpha 1}-\frac{k_{v} k_{i}}{C}\left(i_{-\alpha f}\right) \\
v_{-\alpha}=\left(\left\|v_{-\alpha \beta 1}\right\|-\sqrt{2} V_{n}\right) \frac{v_{-\alpha 1}}{\left\|v_{-\alpha \beta 1}\right\|} \\
v_{-\beta}=-\left(\left\|v_{-\alpha \beta 1}\right\|-\sqrt{2} V_{n}\right) \frac{v_{-\beta 1}}{\left\|v_{-\alpha \beta 1}\right\|}
\end{gathered}
$$

where, $i_{-\alpha f}, i_{-\beta f}$ are the $\alpha$ and $\beta$ components of the feedback.

\section{Oscillator for the zero sequence control voltages}

The nominal frequency and the voltage amplitude of the oscillator which produces the zero sequence control voltages are $\omega_{n}$ and 0 respectively. The oscillator is presented by

$$
\dot{v}_{0 \alpha 1}=\frac{\xi}{k_{v}^{2}}\left(2 V_{n}^{2}-\left\|v_{0 \alpha \beta 1}\right\|^{2}\right) v_{0 \alpha 1}+\omega_{n} v_{0 \beta 1}+\frac{k_{v} k_{i}}{C}\left(i_{0 \beta f}\right)
$$

$$
\begin{gathered}
\dot{v}_{0 \beta 1}=\frac{\xi}{k_{v}^{2}}\left(2 V_{n}^{2}-\left\|v_{0 \alpha \beta 1}\right\|^{2}\right) v_{0 \beta 1}-\omega_{n} v_{0 \alpha 1}-\frac{k_{v} k_{i}}{C}\left(i_{0 \alpha f}\right) \\
v_{0 \alpha}=\left(\left\|v_{0 \alpha \beta 1}\right\|-\sqrt{2} V_{n}\right) \frac{v_{0 \alpha 1}}{\left\|v_{0 \alpha \beta 1}\right\|} \\
v_{0 \beta}=\left(\left\|v_{0 \alpha \beta 1}\right\|-\sqrt{2} V_{n}\right) \frac{v_{0 \beta 1}}{\left\|v_{0 \alpha \beta 1}\right\|}
\end{gathered}
$$

where, $i_{0 \alpha f}, i_{0 \beta f}$ are the $\alpha$ and $\beta$ components of the feedback.

\section{Three-phase control voltage}

The positive, negative, and zero sequence control voltages are derived from (11)-(20) as

$$
\begin{aligned}
& {\left[\begin{array}{l}
v_{+a} \\
v_{+b} \\
v_{+c}
\end{array}\right]=\left[\begin{array}{cc}
1 & 0 \\
-\frac{1}{2} & \frac{\sqrt{3}}{2} \\
-\frac{1}{2} & -\frac{\sqrt{3}}{2}
\end{array}\right]\left[\begin{array}{l}
v_{+\alpha} \\
v_{+\beta}
\end{array}\right] ;\left[\begin{array}{l}
v_{+a q} \\
v_{+b q} \\
v_{+c q}
\end{array}\right]=\left[\begin{array}{cc}
1 & 0 \\
-\frac{1}{2} & \frac{\sqrt{3}}{2} \\
-\frac{1}{2} & -\frac{\sqrt{3}}{2}
\end{array}\right]\left[\begin{array}{c}
-v_{+\beta} \\
v_{+\alpha}
\end{array}\right]} \\
& {\left[\begin{array}{l}
v_{-a} \\
v_{-b} \\
v_{-c}
\end{array}\right]=\left[\begin{array}{cc}
1 & 0 \\
-\frac{1}{2} & \frac{\sqrt{3}}{2} \\
-\frac{1}{2} & -\frac{\sqrt{3}}{2}
\end{array}\right]\left[\begin{array}{l}
v_{-\alpha} \\
v_{-\beta}
\end{array}\right] ;\left[\begin{array}{l}
v_{-a q} \\
v_{-b q} \\
v_{-c q}
\end{array}\right]=\left[\begin{array}{cc}
1 & 0 \\
-\frac{1}{2} & \frac{\sqrt{3}}{2} \\
-\frac{1}{2} & -\frac{\sqrt{3}}{2}
\end{array}\right]\left[\begin{array}{c}
v_{-\beta} \\
-v_{-\alpha}
\end{array}\right]} \\
& \left(\begin{array}{l}
v_{0 a} \\
v_{0 b} \\
v_{0 c}
\end{array}\right]=\left[\begin{array}{l}
1 \\
1 \\
1
\end{array}\right]\left[v_{0 \alpha}\right] ;\left[\begin{array}{l}
v_{0 a q} \\
v_{0 b q} \\
v_{0 c q}
\end{array}\right]=\left[\begin{array}{l}
1 \\
1 \\
1
\end{array}\right]\left[\begin{array}{ll}
v_{0 \beta}
\end{array}\right]
\end{aligned}
$$

where, $v_{+a b c q}, v_{-a b c q}, v_{0 a b c q}$ are the lagging orthogonal components of $v_{+a b c}, v_{-a b c}, v_{0 a b c}$. The three-phase control voltages are obtained as

$$
\begin{gathered}
v_{a}^{*}=v_{+a}+v_{-a}+v_{0 a} ; v_{a q}^{*}=v_{+a q}+v_{-a q}+v_{0 q} \\
v_{b}^{*}=v_{+b}+v_{-b}+v_{0 b} ; v_{b q}^{*}=v_{+b q}+v_{-b q}+v_{0 q} \\
v_{c}^{*}=v_{+c}+v_{-c}+v_{0 c} ; v_{c q}^{*}=v_{+c q}+v_{-c q}+v_{0 q}
\end{gathered}
$$

where, $v_{a b c q}^{*}$ are the lagging orthogonal component of $v_{a b c}^{*}$.

\section{E. Generation of feedback currents}

The reference current for individual phases are derived as

$$
\left[\begin{array}{c}
i_{x}^{*} \\
i_{x q}^{*}
\end{array}\right]=\frac{2}{\left(v_{x}^{*}\right)^{2}+\left(v_{x q}^{*}\right)^{2}}\left[\begin{array}{cc}
v_{x}^{*} & v_{x q}^{*} \\
v_{x q}^{*} & -v_{x}^{*}
\end{array}\right]\left[\begin{array}{c}
P_{x}^{*} \\
Q_{x}^{*}
\end{array}\right] ; x \in a, b, c
$$

where, $P_{a}^{*}, P_{b}^{*}, P_{c}^{*}$ and $Q_{a}^{*}, Q_{b}^{*}, Q_{c}^{*}$ are the reference active and reactive power of individual phases (i.e. phase-a,b and c). The current feedbacks are derived as

$$
i_{a f}=i_{a \_i n v}-i_{a}^{*} ; i_{b f}=i_{b_{i n v}}-i_{a}^{*} ; i_{c f}=i_{c_{-} i n v}-i_{c}^{*}
$$

where, $i_{a b c_{-} \text {inv }}$ are the current output of the inverter. The feedback to the positive, negative, and zero sequence oscillators are generated by instantaneous symmetrical component transformation as

$$
\begin{gathered}
A=e^{\frac{2}{3} \pi j} ; A^{2}=e^{\frac{4}{3} \pi j} \\
{\left[\begin{array}{c}
i_{+a f} \\
i_{+b f} \\
i_{+c f}
\end{array}\right]=\frac{1}{3}\left[\begin{array}{ccc}
1 & a & A^{2} \\
A^{2} & 1 & A \\
A & A^{2} & 1
\end{array}\right]\left[\begin{array}{l}
i_{a f} \\
i_{b f} \\
i_{c f}
\end{array}\right]} \\
{\left[\begin{array}{c}
i_{-a f} \\
i_{-b f} \\
i_{-c f}
\end{array}\right]=\frac{1}{3}\left[\begin{array}{ccc}
1 & A^{2} & A \\
A & 1 & A^{2} \\
A^{2} & A & 1
\end{array}\right]\left[\begin{array}{l}
i_{a f} \\
i_{b f} \\
i_{c f}
\end{array}\right]} \\
i_{0 f}=\frac{1}{3}\left(i_{a f}+i_{b f}+i_{c f}\right)
\end{gathered}
$$




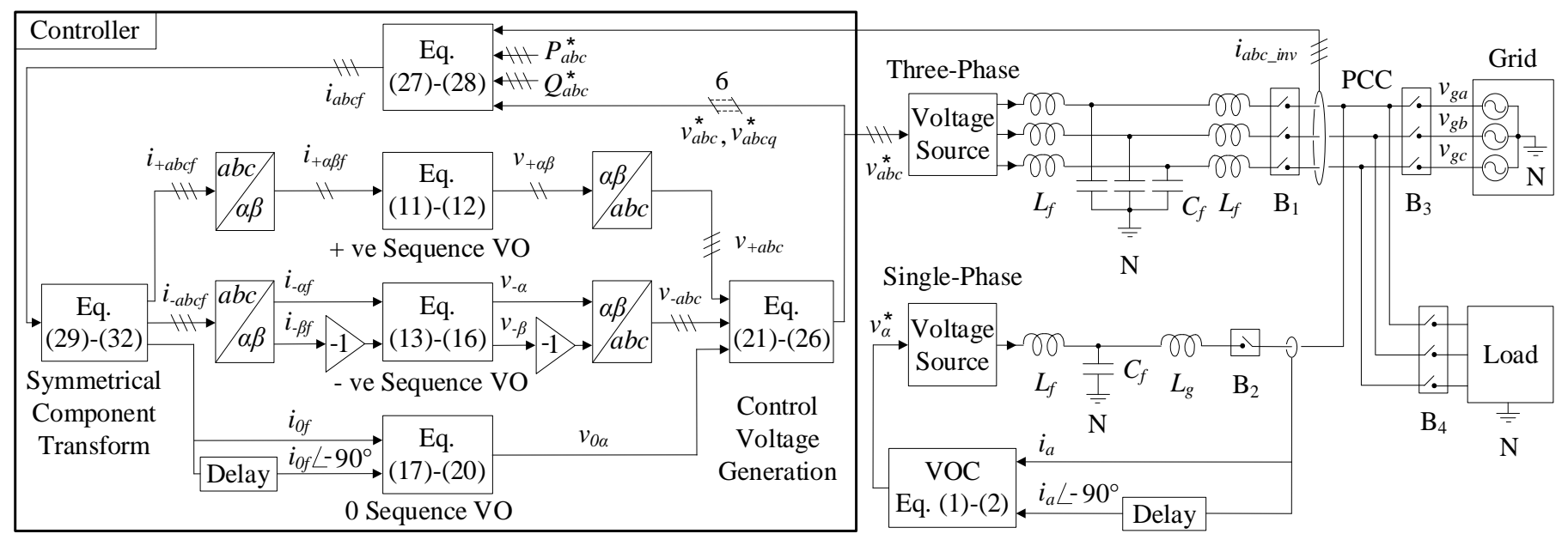

Fig. 6. The proposed instantaneous symmetrical component based virtual oscillator based controller

\section{F. Steady-state frequency and voltage regulation}

The steady-state $\omega$-P, V-Q droops of individual sequences are recovered by time-averaging (11)-(20). The active and reactive powers of individual sequences are taken as

$$
\begin{aligned}
& P_{+}=P_{a+}+P_{b+}+P_{c+} ; Q_{+}=Q_{a+}+Q_{b+}+Q_{c+} \\
& P_{-}=P_{a-}+P_{b-}+P_{c-} Q_{-}=Q_{a-}+Q_{b-}+Q_{c-} \\
& P_{0}=P_{a 0}+P_{b 0}+P_{c 0} ; Q_{0}=Q_{a 0}+Q_{b 0}+Q_{c 0}
\end{aligned}
$$

Next, by using the properties of symmetrical components it can be written that

$$
\begin{aligned}
& P_{a+}=P_{b+}=P_{c+} ; Q_{a+}=Q_{b+}=Q_{c+} \\
& P_{a-}=P_{b-}=P_{c-} ; Q_{a-}=Q_{b-}=Q_{c-} \\
& P_{a 0}=P_{b 0}=P_{c 0} ; Q_{a 0}=Q_{b 0}=Q_{c 0}
\end{aligned}
$$

The regulation of the positive sequence is given by

$$
\begin{gathered}
\omega_{+}=\omega_{n}-\frac{k_{v} k_{i}}{3 C V_{+}^{2}}\left(P_{+}-P_{+}^{*}\right) \\
0=\frac{\xi}{k_{v}^{2}} V_{+}\left(2 V_{n}^{2}-2 V_{+}^{2}\right)-\frac{k_{v} k_{i}}{3 C V_{+}}\left(Q_{+}-Q_{+}^{*}\right)
\end{gathered}
$$

The regulation of the negative sequence is given by

$$
\begin{gathered}
\omega_{-}=\omega_{n}-\frac{k_{v} k_{i}}{3 C\left(V_{-1}\right)^{2}}\left(P_{-}-P_{-}^{*}\right) \\
0=\frac{\xi}{k_{v}^{2}} V_{-1}\left(2 V_{n}^{2}-2 V_{-1}^{2}\right)-\frac{k_{v} k_{i}}{3 C V_{-1}}\left(Q_{-}-Q_{-}^{*}\right) \\
V_{-}=V_{-1}-V_{n}
\end{gathered}
$$

The regulation of the zero sequence is given by

$$
\begin{gathered}
\omega_{0}=\omega_{n}-\frac{k_{v} k_{i}}{3 C\left(V_{01}\right)^{2}}\left(P_{0}-P_{0}^{*}\right) \\
0=\frac{\xi}{k_{v}^{2}} V_{01}\left(2 V_{n}^{2}-2 V_{01}^{2}\right)-\frac{k_{v} k_{i}}{3 C V_{01}}\left(Q_{0}-Q_{0}^{*}\right) \\
V_{0}=V_{01}-V_{n}
\end{gathered}
$$

The frequency and voltage regulation characteristics of the individual sequences are plotted in Fig. 7 and Fig. 8. The negative and zero sequence droops coincide.

\section{G. Transient Dynamics}

The transient characteristics of the proposed VOC can be quantified using voltage rise time, $t_{\text {rise }}$ and active power time constant, $\tau$. The proposed VOC consists of three Andronov-

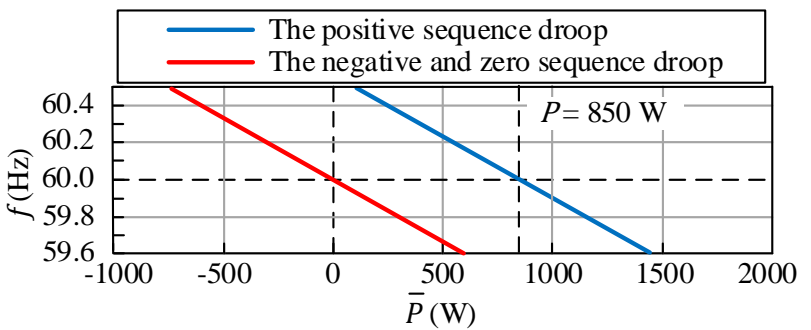

Fig. 7. Steady-state frequency regulation of individual sequences

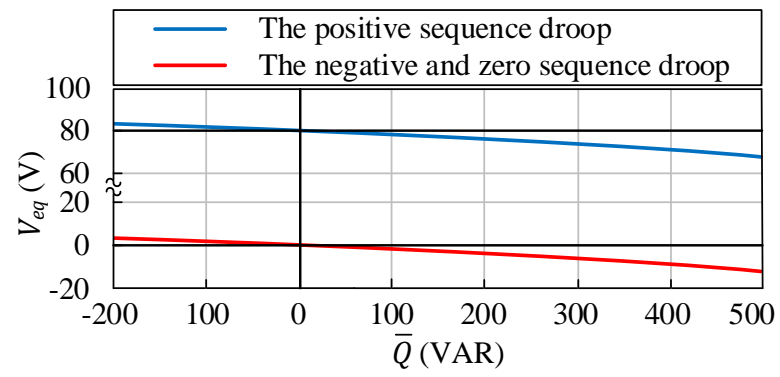

Fig. 8. Steady-state voltage regulation of individual sequences

Hopf oscillators. The rise time of the oscillators are recovered as it is presented in [12]

$$
t_{\text {rise }}=\frac{3 k_{v}^{2}}{2 \xi V_{n}^{2}}
$$

Andronov-Hopf oscillator has approximately first-order active power dynamics [12]. In an inductive electrical network, the active power time constants of individual sequences are recovered as it is derived in [12]

$$
\begin{gathered}
\tau_{z}=\frac{C X_{z}}{k_{v} k_{i}} ;(Z \in+,-, 0) \\
X=\omega_{n}\left(L_{f}+L_{g}\right)
\end{gathered}
$$

IV. Simulation Study: The Proposed VOC in GRidSupPorting Mode in PResence of Unbalanced Grid VOLTAGES

A simulation study is presented in this Section. The proposed instantaneous symmetrical component based VOC is used for grid-supporting operation in presence of unbalanced grid voltages. The schematic diagram is presented in Fig. 6. The three-phase source is connected to the grid using the breakers, 
$\mathrm{B} 1$ and B3. The RL load is connected to the PCC using the breaker, B4. The breaker, B2 is kept off. The waveforms of the output source currents when $\left(\left|V_{g a}\right|=\left|V_{g b}\right|=\left|V_{g c}\right|=1\right.$ P.U.) and ( $\left|V_{g a}\right|=0.9$ P.U.; $\left|V_{g b}\right|=\left|V_{g c}\right|=1$ P.U.) are shown in Fig. 9 (a). The phasor diagrams of the output phase currents of the voltage source and the phase voltages of the grid are presented in Fig. 9. (b) and (c). In presence of unbalanced grid voltages, the three-phase voltage source supports phase-a by injecting reactive power. The active and reactive power outputs of phase$\mathrm{b}$ and phase-c are stabilized very close to the reference.

$|\mathrm{Va}|$ at PCC is changed from 1P.U to 0.9 P.U

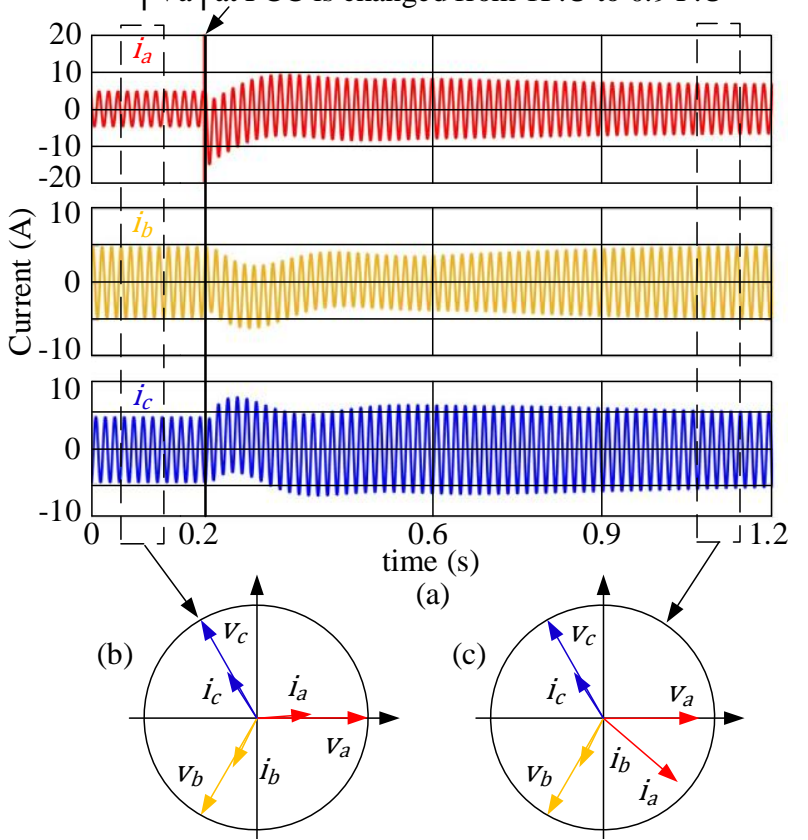

Fig. 9. The Proposed VOC in grid-supporting mode: (a) Output currents of individual phases in presence of balanced and unbalanced grid voltage; Relative phase angles between voltages and currents in presence of (b) balanced grid voltage (c) unbalanced grid voltage

\section{A. The proposed VOC: Reactive power droop response in presence of unbalanced grid voltages}

The solid black line in Fig. 10 represents the desired reactive power droop characteristic (10). The actual reactive power outputs of individual phases in the presence of the different unbalanced grid voltages are also plotted. The operating points follow the desired reactive power droop characteristic closely. The reactive power droop response of the existing and proposed VO controller in presence of different unbalanced grid voltages are presented in Fig. 4 and Fig. 10 respectively. The performance of the proposed VOC is better.

\section{B. The proposed VOC: Active power droop response in} presence of unbalanced grid voltage

The solid red and blue lines in Fig. 11 represent the desired active power droop characteristic (9) when the voltage amplitude is 1 P.U. and 0.85 P.U. respectively.

The actual active power outputs of individual phases in presence of the different unbalanced grid voltages are also plotted. The frequency of the grid is kept constant at $60 \mathrm{~Hz}$. The operating points of all three phases stay very close to the point, $(283.33,60)$ in presence of the different unbalanced grid voltages. The active power droop response of the existing and proposed VO controller in presence of different unbalanced grid voltages are presented in Fig. 5 and Fig. 11 respectively. The performance of the proposed VOC is better.

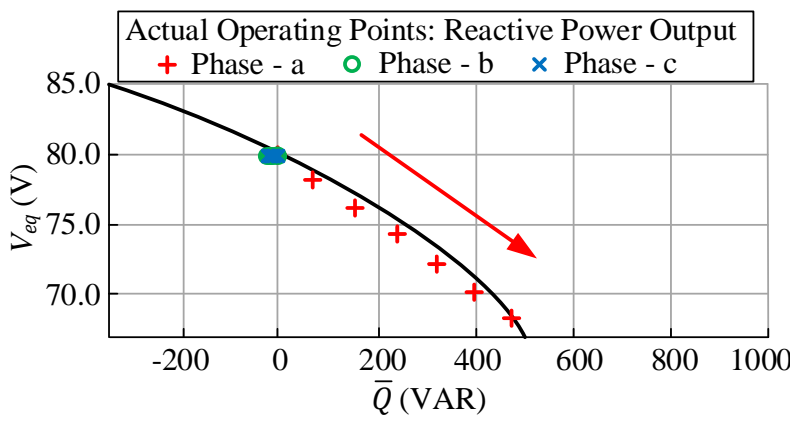

Fig. 10. Grid-supporting performance of the proposed VOC in presence of unbalanced grid voltages: desired reactive power droop characteristic and the actual operating points

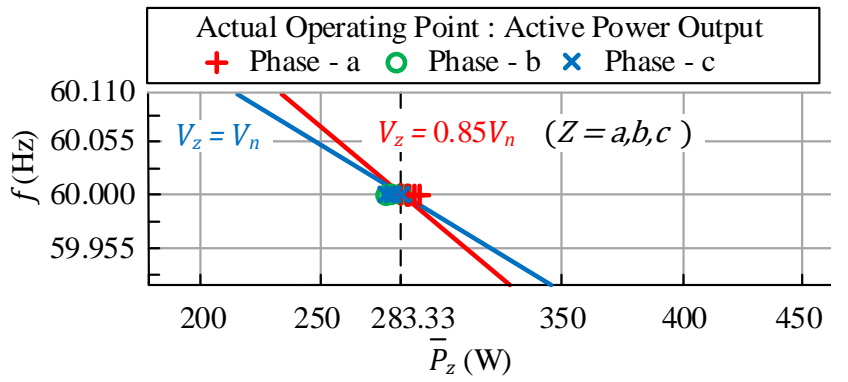

Fig. 11. Grid-supporting performance of the proposed VOC in presence of unbalanced grid voltage: desired active power droop characteristic and actual operating points

\section{HARDWARE EXPERIMENTS AND DISCUSSIONS}

The schematic diagram and the picture of the experimental setup are shown in Fig. 12. (a) and (b). The specifications of the experimental setup are presented in Table II.

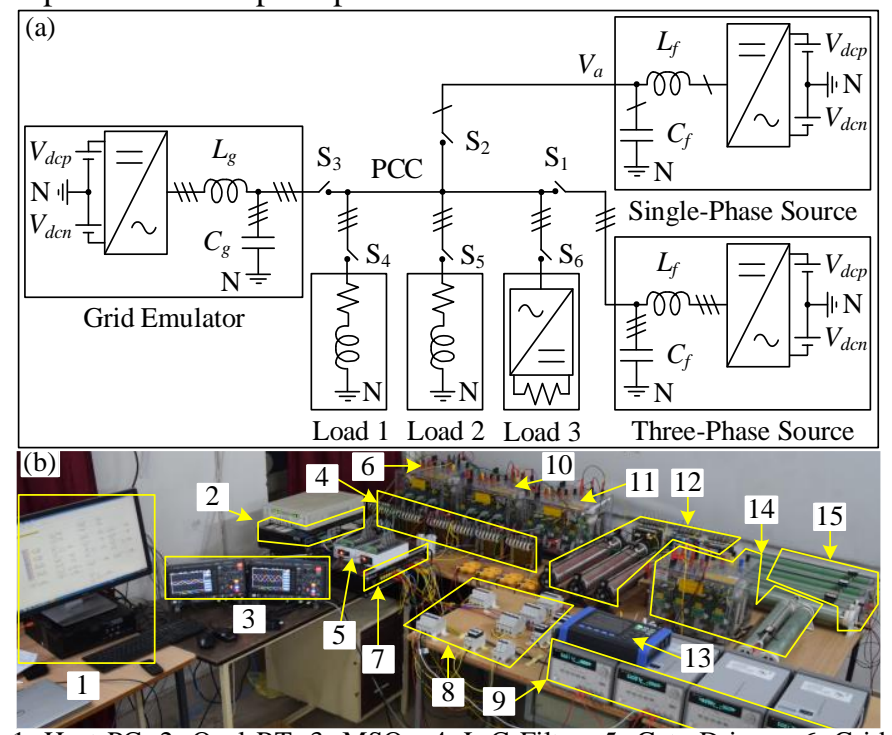

1. Host PC, 2. Opal-RT, 3. MSOs, 4. L-C Filters 5. Gate Drivers, 6. Grid Emulator, 7. Sensors, 8. Breakers, 9. dc-Sources, 10. 3- $\phi$ Inverter, 11. 1- $\phi$ Inverter, 12. Load 1, 13. Power Analyzer, 14. Load 3, 15. Load 2

Fig. 12. Experimental Setup: (a) schematic diagram (b) picture of the hardware setup in the laboratory

The three-phase inverter is connected to the grid emulator using the breakers, $S_{1}$ and $S_{3}$. The R-L load (Load 1) is connected to the PCC using the breaker, $\mathrm{S}_{4}$. The reference active power per phase is set to $120 \mathrm{~W}$. Primarily, the 
amplitudes of the individual phase voltages of the grid emulator are set to 1 P.U. The voltage profile of the PCC is shown in Fig. 13. The grid emulator moderately behaves like a week grid due to the presence of the filter inductors, $L_{g}$.

Table II: Specifications of hardware experimental setup

\begin{tabular}{lll}
\hline \hline Symbol & Description & Value \\
\hline$V_{n g}$ & Nominal voltage: grid emulator & $50 \mathrm{~V}$ \\
$\omega_{n g}$ & Nominal frequency: grid emulator $2 \pi 50 \mathrm{rad} / \mathrm{s}$ \\
$L_{g}$ & Filter inductor: grid emulator & $2 \mathrm{mH} / \mathrm{Phase}$ \\
$C_{g}$ & Filter capacitor: grid emulator & $20 \mu \mathrm{F} / \mathrm{Phase}$ \\
$L_{f}$ & Filter inductor: sources & $2 \mathrm{mH} / \mathrm{Phase}$ \\
$C_{f}$ & Filter capacitor: sources & $20 \mu \mathrm{F} / \mathrm{Phase}$ \\
$V_{d c p}, V_{d c p}$ dc-link voltages (split Capacitor) & $100 \mathrm{~V}$ \\
Load 1 & Linear RL load & $12.5-22 \Omega+10 \mathrm{mH} / \mathrm{Phase}$ \\
Load 2 & Linear RL load & $15-40 \Omega+10 \mathrm{mH} / \mathrm{Phase}$ \\
Load 3 & Non-liner Load: rectifier & $15-35 \Omega$ at dc-link \\
\hline \hline
\end{tabular}

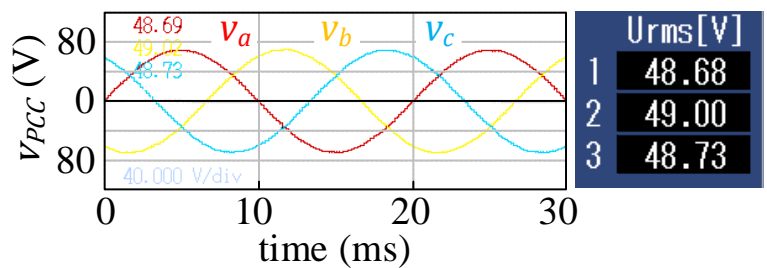

Fig. 13. The voltage profile of PCC: in presence of balanced grid voltages

A. Grid supporting operation: reactive power support in presence of unbalanced grid voltages

Next, at $\mathrm{t}=150 \mathrm{~ms}$ the voltage amplitude of phase-a of the grid emulator is reduced to 0.85 P.U. The voltage amplitudes of phase-b and phase-c of the grid emulator are kept constant to 1 P.U. The voltage profile of the PCC in presence of unbalanced grid voltages is shown in Fig. 14.

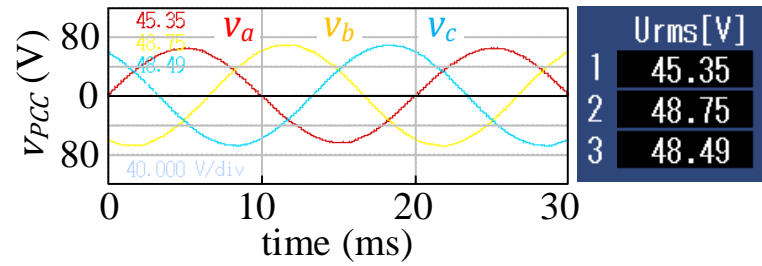

Fig. 14. The voltage profile of PCC: in presence of unbalanced grid voltages

The voltage of PCC at phase-a is not reduced by $15 \%$. It is reduced only by $6.8 \%$ approximately because the gridconnected three-phase inverter supports phase-a of the PCC with reactive power. The active and reactive power outputs in presence of balanced and unbalanced grid voltages are shown in Fig. 15. (a) and (b) respectively. The waveforms of the output phase currents of the three-phase inverter are shown in Fig. 16. (a). The relative angles among the phase voltages of the PCC and the output phase currents of the three-phase inverter are captured using a power analyzer and presented in Fig. 16. (b) and (c). In presence of balanced grid voltages, the inverter injects active power into the grid emulator. The power factors of all individual phases are very close to unity. At $t=150 \mathrm{~ms}$ the voltage amplitude of phase-a of the grid emulator is reduced to 0.85 P.U. In presence of the unbalanced grid voltages, the inverter starts supplying reactive power to phase-a of the PCC with a very minimum initial transient. The amplitude and phase of the output currents of phase-b and phase-c remain nearly unchanged. The actual active power outputs of all three phases remain close to the reference value. The active power output of the inverter at phase-a is increased with the increase in the reactive power output of phase-a. It is because that the grid is a week grid. The active and the reactive power outputs are not completely decoupled.

\begin{tabular}{|c|c|c|c|c|c|}
\hline & $\mathrm{P}[\mathrm{W}]$ & $\mathrm{Q}[$ var ] & & $\mathrm{P}[\mathrm{W}]$ & $\mathrm{Q}$ [var] \\
\hline 1 & $0.12 \mathrm{k}$ & $-\quad 0.02 k$ & 1 & $0.15 \mathrm{k}$ & $0.07 \mathrm{k}$ \\
\hline 2 & $0.12 \mathrm{k}$ & $-0.02 k$ & 2 & $0.11 \mathrm{k}$ & - $\quad 0.01 k$ \\
\hline 3 & $0.12 \mathrm{k}$ & - $\quad 0.01 k$ & 3 & $0.11 \mathrm{k}$ & $0.01 \mathrm{k}$ \\
\hline
\end{tabular}

Fig. 15. The active and reactive power outputs of individual phases (a) In presence of balanced grid voltages (b) unbalanced grid voltages

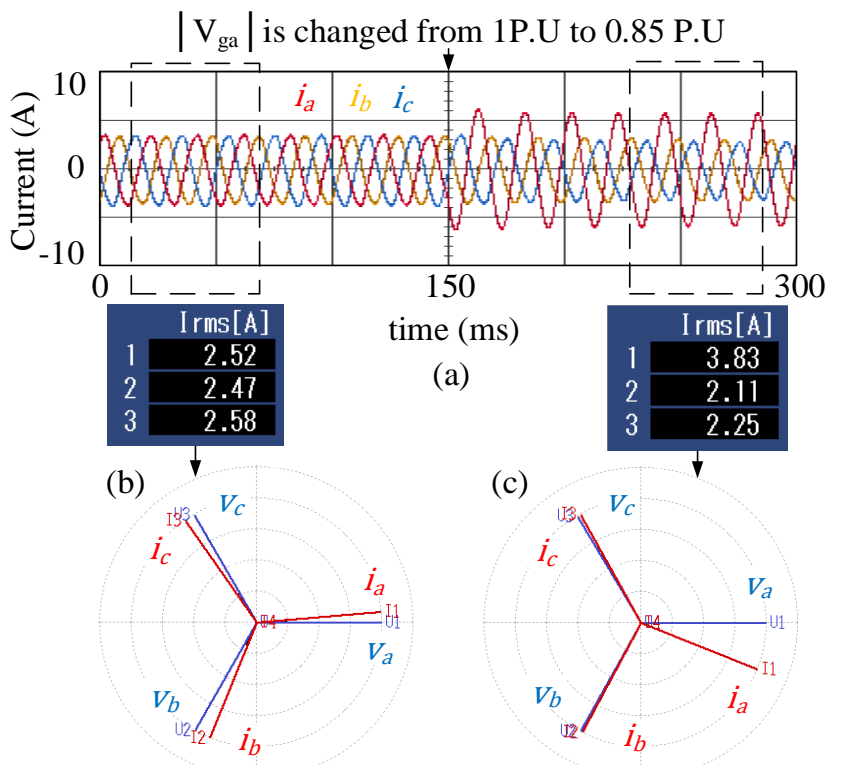

Fig. 16. The proposed VOC in grid-supporting operation: (a) the output phase currents of the three-phase inverter in presence of balanced and unbalanced grid voltages (b) the relative phase angles among the phase voltages of the PCC and the output phase currents of the three-phase inverter

Next, the amplitude of the grid-voltage of phase-a is kept at 1 P.U., and the amplitude of the grid-voltages of phase-b and phase-c is reduced to 0.9 P.U. The waveforms of the output currents of the inverter are shown in Fig. 17. It is observed that the inverter starts supporting phase-b and phase-c with leading currents.

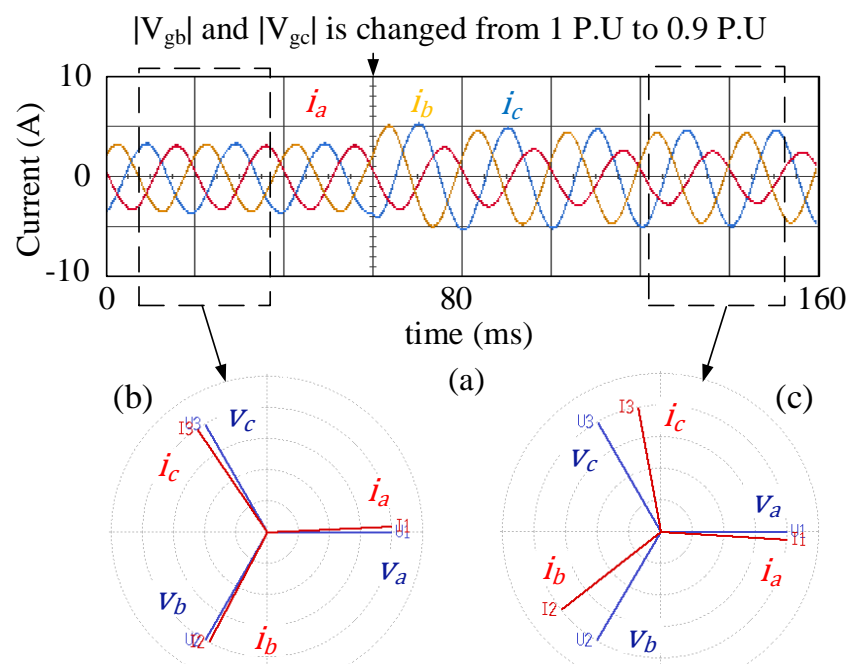

Fig. 17. The proposed VOC in grid-supporting operation: amplitude of gridvoltage of phase-b and phase-c is reduced to 0.9 P.U (a) the output phase currents of the three-phase inverter in presence of balanced and unbalanced grid voltages (b) the relative phase angles among the phase voltages of the PCC and the output phase currents of the three-phase inverter 
B. Grid forming operation: integration of a single-phase and a three-phase source into the same system

The three-phase inverter is connected to the PCC using the breaker $\mathrm{S}_{1}$. The single-phase inverter, with proper droop, is connected to phase-a of the PCC using the breaker, $S_{2}$ to share half of the load of phase-a. The breaker, $S_{3}$ is kept off.

The steady-state output currents of the three-phase and the single-phase inverters are shown in Fig. 18. (a) and (b) when the linear load (Load 1) and non-linear load (Load 3) are connected to the PCC respectively.
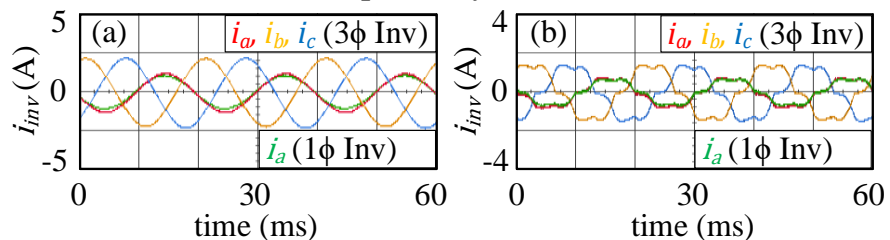

Fig. 18. The output currents of the three-phase and single-phase inverters in grid-forming mode with (a) linear load (b) non-linear load

The transient response of the proposed controller during a step change in load at the PCC is shown in Fig. 19. A linear load (Load 2) is connected to the PCC primarily. Then a non-linear load (Load 3) is added to the PCC. The load sharing ratio is maintained by the two inverters with no significant overshoot in the inverter currents.

The transient response of the proposed controller during the synchronization of the two inverters is presented in Fig. 20. At $\mathrm{t}=40 \mathrm{~ms}$ the single-phase inverter is connected to phase-a of the PCC. A pre-synchronization technique for $\mathrm{VOC}$ as proposed in [8] is used. No significant overshoot in the inverter currents is noticed.

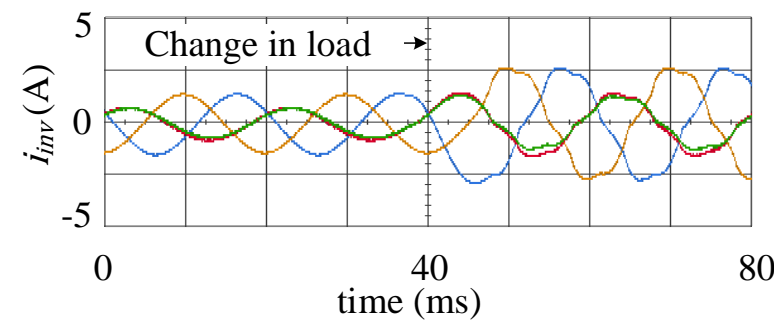

Fig. 19. Output currents of the inverters in grid-forming mode during a step load change at PCC

lime of the integration of the single-phase source

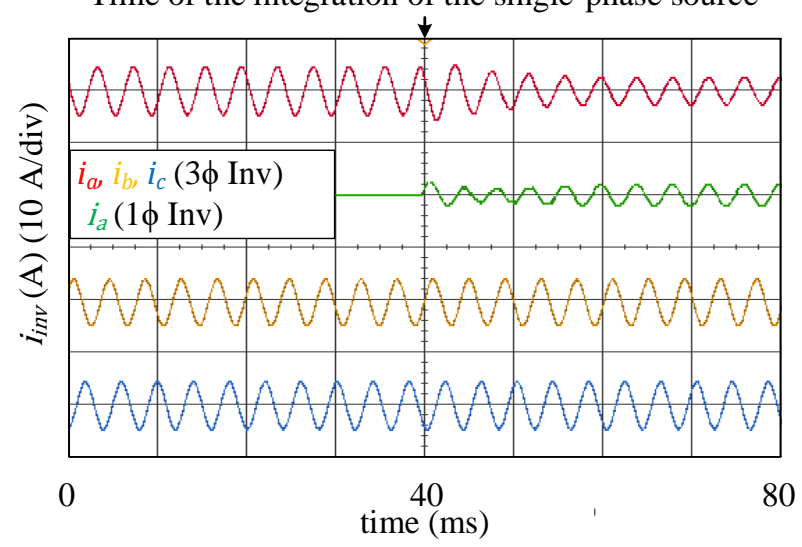

Fig. 20. Output currents of the inverter during the integration of the single-phase inverter with the three-phase inverter in grid-forming mode

Next, two single-phase inverters are connected to phase-b and phase-c respectively for equal load sharing. The waveforms of the inverter currents are shown in Fig. 21. The data is extracted in CSV format from two synchronized MSO and plotted using Matplotlib. Primarily a linear three-phase load is connected to the PCC. Then at $\mathrm{t}=50 \mathrm{~ms}$, a diode bridge rectifier is connected to the PCC. The load sharing ratio is maintained with the linear and non-linear load.

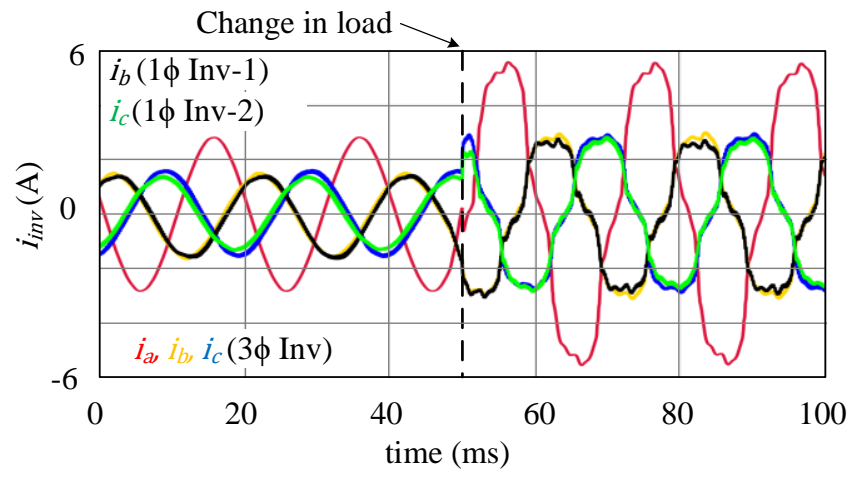

Fig. 21. The output currents of the three-phase and single-phase inverters in grid-forming mode with linear and non-linear load

The improvement in the functionality of the proposed VOC over the existing VOC is summarized in Table III.

Table III: Improved functionality of proposed VOC over existing VOC

\begin{tabular}{l|l|l}
\hline \hline $\begin{array}{l}\text { Functionality } \\
\begin{array}{l}\text { Maximum numbers of output } \\
\text { control voltage components }\end{array}\end{array}$ & Two $(\alpha$ and $\beta)$ & $\begin{array}{l}\text { Three (Positive, Negative, } \\
\text { and Zero sequence) }\end{array}$ \\
\hline $\begin{array}{l}\text { Maximum numbers of } \\
\text { feedback current components } \\
\text { as input }\end{array}$ & Two ( $\alpha$ and $\beta)$ & $\begin{array}{l}\text { Three (Positive, Negative, } \\
\text { and Zero sequence) }\end{array}$ \\
\hline $\begin{array}{l}\text { Provision to generate } \\
\text { unbalanced } \alpha \text { and } \beta \\
\text { components in output control } \\
\text { voltage when required }\end{array}$ & No & Yes \\
\hline $\begin{array}{l}\text { Grid-supporting mode in } \\
\text { presence of unbalanced grid } \\
\text { voltages }\end{array}$ & $\begin{array}{l}\text { Not reported in } \\
\text { the literature }\end{array}$ & $\begin{array}{l}\text { Decent (validated using } \\
\text { simulation study and } \\
\text { hardware experiment) }\end{array}$ \\
\hline $\begin{array}{l}\text { Integration of three-phase and } \\
\text { single-phase inverters into the } \\
\text { same system }\end{array}$ & $\begin{array}{l}\text { Not reported in } \\
\text { the literature }\end{array}$ & $\begin{array}{l}\text { Decent (validated using } \\
\text { hardware experiment) }\end{array}$ \\
\hline \hline
\end{tabular}

\section{CONCLUSION}

This paper has combined the instantaneous symmetrical component theory with the Virtual Oscillator (VO) based control technique for inverters. The combination adds a few important functionalities to VO based controllers (VOCs). The systematic development of the symmetrical component based VOC is presented. The performance of the proposed controller is verified using simulation study and hardware experiments.

\section{REFERENCES}

[1] L. A. B. Tôrres, J. P. Hespanha, and J. Moehlis, "Power supply synchronization without communication," in 2012 IEEE Power and Energy Society General Meeting, Jul. 2012, pp. 1-6.

[2] B. B. Johnson, S. V Dhople, A. O. Hamadeh, and P. T. Krein, "Synchronization of Nonlinear Oscillators in an LTI Electrical Power Network," in IEEE Transactions on Circuits and Systems I: Regular Papers, vol. 61, no. 3, pp. 834-844, Mar. 2014.

[3] L. A. B. Tôrres, J. P. Hespanha and J. Moehlis, "Synchronization of Identical Oscillators Coupled Through a Symmetric Network With Dynamics: A Constructive Approach With Applications to Parallel 
Operation of Inverters," in IEEE Transactions on Automatic Control, vol. 60, no. 12, pp. 3226-3241, Dec. 2015.

[4] M. Sinha, F. Dörfler, B. B. Johnson, and S. V. Dhople, "Uncovering Droop Control Laws Embedded Within the Nonlinear Dynamics of Van der Pol Oscillators," in IEEE Transactions on Control of Network Systems, vol. 4, no. 2, pp. 347-358, Jun. 2017.

[5] B. Johnson, M. Rodriguez, M. Sinha, and S. V. Dhople, "Comparison of virtual oscillator and droop control," in 2017 IEEE 18th Workshop on Control and Modeling for Power Electronics (COMPEL), Jul. 2017, pp. $1-6$.

[6] Z. Shi, J. Li, H. I. Nurdin, and J. E. Fletcher, "Comparison of Virtual Oscillator and Droop Controlled Islanded Three-Phase Microgrids," in IEEE Transactions on Energy Conversion, vol. 34, no. 4, pp. 1769-1780, Dec. 2019.

[7] H. Yu, M. A. Awal, H. Tu, I. Husain, and S. Lukic, "Comparative Transient Stability Assessment of Droop and Dispatchable Virtual Oscillator Controlled Grid-Connected Inverters," in IEEE Transactions on Power Electronics, vol. 36, no. 2, pp. 2119-2130, Feb. 2021.

[8] B. B. Johnson, S. V. Dhople, A. O. Hamadeh, and P. T. Krein, "Synchronization of Parallel Single-Phase Inverters With Virtual Oscillator Control," in IEEE Transactions on Power Electronics, vol. 29, no. 11, pp. 6124-6138, Nov. 2014

[9] B. B. Johnson, M. Sinha, N. G. Ainsworth, F. Dörfler, and S. V. Dhople, "Synthesizing Virtual Oscillators to Control Islanded Inverters," in IEEE Transactions on Power Electronics, vol. 31, no. 8, pp. 6002-6015, Aug. 2016.

[10] G.-S. Seo, M. Colombino, I. Subotic, B. Johnson, D. Groß, and F. Dörfler, "Dispatchable Virtual Oscillator Control for Decentralized Inverterdominated Power Systems: Analysis and Experiments," in 2019 IEEE Applied Power Electronics Conference and Exposition (APEC), Mar. 2019, pp. 561-566.

[11] M. Ali, H. I. Nurdin, and J. Fletcher, "Dispatchable Virtual Oscillator Control for Single-Phase Islanded Inverters: Analysis and Experiments," in IEEE Transactions on Industrial Electronics, vol. 68, no. 6, pp. 48124826, June 2021.

[12] M. Lu, S. Dutta, V. Purba, S. V. Dhople, and B. Johnson, "A Gridcompatible Virtual Oscillator Controller: Analysis and Design," in 2019 IEEE Energy Conversion Congress and Exposition (ECCE), Sep. 2019, pp. 2643-2649.

[13] B. B. Johnson, S. V. Dhople, J. L. Cale, A. O. Hamadeh, and P. T. Krein, "Oscillator-Based Inverter Control for Islanded Three-Phase Microgrids," in IEEE Journal of Photovoltaics, vol. 4, no. 1, pp. 387-395, Jan. 2014.

[14] D. Raisz, T. T. Thai, and A. Monti, "Power Control of Virtual Oscillator Controlled Inverters in Grid-Connected Mode," in IEEE Transactions on Power Electronics, vol. 34, no. 6, pp. 5916-5926, June 2019.

[15] M. Ali, H. I. Nurdin, and J. E. Fletcher, "Output Power Regulation of a Virtual Oscillator Controlled Inverter," in 2018 IEEE 18th International Power Electronics and Motion Control Conference (PEMC), Aug. 2018, pp. 1085-1090.

[16] M. A. Awal, H. Yu, H. Tu, S. M. Lukic, and I. Husain, "Hierarchical Control for Virtual Oscillator Based Grid-Connected and Islanded Microgrids," in IEEE Transactions on Power Electronics, vol. 35, no. 1, pp. 988-1001, Jan. 2020.

[17] M. A. Awal and I. Husain, "Unified Virtual Oscillator Control for GridForming and Grid-Following Converters," in IEEE Journal of Emerging and Selected Topics in Power Electronics, p. 1, 2020.

[18] M. A. Awal and I. Husain, "Transient Stability Assessment for Current Constrained and Unconstrained Fault Ride-Through in Virtual Oscillator Controlled Converters," in IEEE Journal of Emerging and Selected Topics in Power Electronics, vol. 9, no. 4, pp. 4573-4586, Aug. 2021.

[19] M. A. Awal, H. Yu, I. Husain, W. Yu, and S. M. Lukic, "Selective Harmonic Current Rejection for Virtual Oscillator Controlled GridForming Voltage Source Converters," in IEEE Transactions on Power Electronics, vol. 35, no. 8, pp. 8805-8818, Aug. 2020.

[20] S. Luo, W. Wu, E. Koutroulis, H. S.-H. Chung, and F. Blaabjerg, "A New Virtual Oscillator Control Without Third-Harmonics Injection For DC/AC Inverter," in IEEE Transactions on Power Electronics, vol. 36, no. 9, pp. 10879-10888, Sept. 2021.

[21] M. A. Awal, L. D. Flora, and I. Husain, "Observer Based Generalized Active Damping for Voltage Source Converters With LCL Filters," in
IEEE Transactions on Power Electronics, vol. 37, no. 1, pp. 125-136, Jan. 2022.

[22] O. Ajala, M. Lu, S. V. Dhople, B. B. Johnson, and A. Dominguez-Garcia, "Model Reduction for Inverters with Current Limiting and Dispatchable Virtual Oscillator Control," in IEEE Transactions on Energy Conversion, p. 1,2021

[23] J. Lin, "Virtual Oscillator Control of Distributed Power Filters for Selective Ripple Attenuation in DC Systems," in IEEE Transactions on Power Electronics, vol. 36, no. 7, pp. 8552-8560, July 2021.

[24] "IEEE Recommended Practice for Monitoring Electric Power Quality," in IEEE Std 1159-2019 (Revision of IEEE Std 1159-2009), pp. 1-98, Aug. 2019.

[25] S. Gopalan, K. Vasudevan, D. Kumar, and P. Shanmugam, "Impact of Supply Voltage Unbalance and Harmonics on DC Bus Electrolytic Capacitor of Adjustable Speed Drives," in IEEE Transactions on Industry Applications, vol. 56, no. 4, pp. 3819-3830, July 2020.

[26] M. M. Ghahderijani, A. Camacho, C. Moreira, M. Castilla, and L. de Vicuña, "Imbalance-Voltage Mitigation in an Inverter-Based Distributed Generation System Using a Minimum Current-Based Control Strategy," in IEEE Transactions on Power Delivery, vol. 35, no. 3, pp. 1399-1409, June. 2020.

[27] L. Ji, J. Shi, Q. Hong, Y. Fu, X. Chang, Z. Cao, Y. Mi, Z. Li, and C. Booth, "A Multi-Objective Control Strategy for Three Phase Grid-Connected Inverter During Unbalanced Voltage Sag," in IEEE Transactions on Power Delivery, vol. 36, no. 4, pp. 2490-2500, Aug. 2021.

[28] M. M. Shabestary and Y. A.-R. I. Mohamed, "Advanced Voltage Support and Active Power Flow Control in Grid-Connected Converters Under Unbalanced Conditions," in IEEE Transactions on Power Electronics, vol. 33, no. 2, pp. 1855-1864, Feb. 2018.

[29] S. Hasan and V. Agarwal, "An Unconstrained Voltage Support Scheme for Distributed Generation Connected to Resistive-Inductive Grid Under Unbalanced Conditions," in IEEE Transactions on Industry Applications, vol. 57, no. 4, pp. 4253-4262, July 2021.

[30] Q. Sun, J. Zhou, J. M. Guerrero, and H. Zhang, "Hybrid ThreePhase/Single-Phase Microgrid Architecture With Power Management Capabilities," IEEE Transactions on Power Electronics, vol. 30, no. 10, pp. 5964-5977, Oct. 2015.

[31] Y. A. Kuznetsov, "Andronov-Hopf bifurcation," in Scholarpedia, vol. 1, no. 10 , p. 1858 , Oct. 2006. 